\title{
ANARCOSINDICALISMO, RESISTENCIA Y GRUPOS DE AFINIDAD. LA COMISIÓN DE PROPAGANDA CONFEDERAL Y ANARQUISTA (1937-1939)
}

\author{
Anarcho-syndicalism, resistance and affinity groups: \\ Comisión de Propaganda Confederaly Anarquista (1937-1939)
}

\begin{abstract}
Isaac MARTín NiETO
isaacmartin@usal.es

Departamento de Historia Medieval, Moderna y Contemporánea

Universidad de Salamanca
\end{abstract}

Fecha de recepción: $20-01-2010$

Fecha de aceptación: 29-01-2010

RESUMEN: Durante la Guerra Civil española (1936-1939), casi todos los miembros de los comités dirigentes de la Confederación Nacional del Trabajo (CNT) y de la Federación Anarquista Ibérica (FAI) militaban en algún grupo de afinidad, institución específicamente anarquista que permitía a sus miembros forjar esferas de influencia propias al otorgarles una disciplina interna y unas aspiraciones políticas comunes.

Considerando que, a pesar de ello, la historiografía aún no ha integrado el análisis de las dinámicas grupales en el estudio del anarcosindicalismo, este trabajo pretende, además de destacar la potencialidad del nuevo enfoque interpretativo, demostrar la importancia de las relaciones de afinidad anarquista para explicar la fractura del apoyo libertario a la política de resistencia impulsada por el Gobierno de la República en guerra del doctor Negrín (19371939), centrando el análisis en las dialécticas de poder desatadas en torno a la Comisión de Propaganda Confederal y Anarquista del Centro.

Palabras Clave: Guerra Civil española, anarcosindicalismo, CNT, FAI, grupo de afinidad, propaganda.

ABSTRACT: During the Spanish Civil War (1936-1939), almost all the members of the leader committees of the Confederación Nacional del Trabajo (CNT) and of the Fede- 
ración Anarquista Ibérica (FAI) were also members of some affinity group. This was a specifically anarchistic institution in which their members could forge their own spheres of influence by the means of the group's internal discipline and common political aspirations.

Considering that, in spite of its importance, historiography has not integrated yet the analysis of group dynamics in the study of anarchosyndicalism, this work will emphasize the potential of this new interpretive approach and demonstrate the importance of the relations of anarchistic affinity to explain the fracture of the libertarian support to the policy of resistance stimulated by the Government of the Republic in war of doctor Negrín (19371939). The analysis will be focused on the dialectics of power untied around the Comision de Propaganda Confederal y Anarquista del Centro.

Keywords: Spanish Civil War, Anarchosyndicalism, CNT, FAI, Affinity group, Propaganda.

$\mathrm{Al}$ abordar el estudio del anarquismo español, la necesidad de zafarse de todo apriorismo ontológico se torna imperiosa. La complejidad de la estructura organizativa de este movimiento social exige a los historiadores encontrar los instrumentos de análisis que más se adecuen a su naturaleza, diversa y heterogénea. En los últimos años, algunas investigaciones pioneras han ido perfilando las líneas maestras de una metodología fundada sobre esta realidad. La clave de esta nueva perspectiva radica en el análisis de las dinámicas internas asociadas a los grupos de afinidad. Compuestos de unas diez personas, estos grupos se definían por una visión política y doctrinaria común, una disciplina interna que otorgaba homogeneidad a sus acciones y una posición de poder condicionada por sus coordenadas en el entramado institucional libertario y por sus relaciones con el resto de los grupos ${ }^{1}$.

En consonancia con esta línea de investigación, el trabajo presente analizará la influencia de las dinámicas grupales en la fractura del compromiso libertario con la política de resistencia del Gobierno Negrín. Para ello, nos centraremos en el estudio del organismo responsable de controlar la propaganda en Madrid, la Comisión de Propaganda Confederal y Anarquista de la Región Centro.

El 17 de mayo de 1937 el socialista Juan Negrín asumió la Jefatura del Gobierno de la República sustituyendo a Largo Caballero. La estrategia para la victoria del nuevo presidente consistía en el robustecimiento de los pilares sobre los que se asentaba la resistencia frente a las tropas franquistas, el Ejército Popular y el Frente Popular, y en la búsqueda del apoyo de las potencias democráticas occidentales, Francia y Reino Unido, refugiadas en la política de No Intervención. En la primavera de 1938 hubo que bajar la apuesta. La partición de la zona republicana en marzo y el pacto anglo-italiano en abril demostraron que la victoria ya no era factible. La resistencia sólo se manten- 
dría por la necesidad de alcanzar una posición de fuerza en la que sustentar una negociación para liquidar la guerra cuyos términos se explicitaron en los célebres Trece Puntos del $1^{\circ}$ de mayo. Tras la caída de Cataluña, la política negrinista sufrió un nuevo recorte. En la última reunión de las Cortes republicanas, el 1 de febrero de 1939 en Figueras, los trece puntos fueron condensados en tres, siendo el más importante la exigencia de evitar toda represalia por parte del bando vencedor. De todas maneras, la paz consensuada ya no era posible. La política elusiva y hostil de las potencias democráticas y la exigencia franquista de una rendición incondicional convirtieron a la resistencia en el único medio de asegurar la evacuación y la salvación de las personas más comprometidas con la coalición defensora de la República².

Traumatizada por los Hechos de Mayo de 1937 y apartada del Gobierno, la Confederación Nacional del Trabajo (CNT) no volvería a sentarse en el Consejo de Ministros hasta abril de 1938. Una vez que fueron absorbidas las derivas radicales que preconizaban la oposición integral al nuevo gabinete, el Comité Nacional de la CNT (CN/CNT) reasumió el objetivo de compartir la responsabilidad de la guerra con el resto de las fuerzas antifascistas, comenzando los acercamientos a Negrín a inicios de junio. Con la publicación de un programa propio para la victoria y el impulso del proyecto del Frente Popular Antifascista, alternativo al Frente Popular Nacional, la CNT no hizo más que fortalecer su posición de cara a las negociaciones para el reingreso en el Gobierno. El respaldo a esta política por parte de los comités dirigentes del anarcosindicalismo llegó con el Pleno Nacional de Regionales del Movimiento Libertario celebrado en Valencia en septiembre de 1937. El secretario del CN/CNT, Mariano R. Vázquez, consiguió la aprobación de un dictamen que renovaba el compromiso anarquista con el frentepopulismo de guerra, consistente en la subordinación de los objetivos políticos al triunfo bélico, y la elaboración de un Manifiesto que incidía en la necesidad de "nuestra presencia en el Poder" 3 . La demoledora ofensiva franquista sobre el Bajo Aragón de marzo de 1938 aceleró el proceso. El programa de unidad de acción firmado por la CNT y la UGT (Unión General de Trabajadores) el día 18 configuró un frente único concentrado en la reincorporación a las tareas gubernamentales. Aumentó el ritmo de las reuniones con el resto de las organizaciones políticas, en busca de una salida a la tambaleante situación militar. Se amplió la base del Frente Popular Nacional con la adhesión de la CNT y de la FAI (Federación Anarquista Ibérica). Finalmente, el 6 de abril las dos centrales sindicales ingresaron en el nuevo Gobierno de Unión Nacional y de Guerra4.

Con la vuelta al gobierno, la CNT selló su compromiso con la política de resistencia. El secretario del CN/CNT culminó la línea colaboracionista y frentepopulista del anarcosindicalismo con la asunción de los Trece Puntos. El 24 de junio de 1938 pronunció un discurso en calidad de representante 
de la CNT en el Frente Popular en el que hizo suyas las bases de la declaración ministerial del $1^{\circ}$ de mayo: señaló la unidad sindical y el apoyo al Gobierno como las bases de la unidad de la retaguardia, reivindicó los valores democráticos de la República en guerra y defendió que el pueblo español luchaba "por la independencia, por la libertad, la justicia, el pan, el bienestar colectivo y por la independencia de los pueblos, para que se rijan autónomamente, dentro de la unidad nacional [...]. Así se afirma en los fines de guerra de la declaración del Gobierno". De nuevo un Pleno de Regionales del Movimiento Libertario, el celebrado en octubre de 1938, sirvió para refrendar la línea marcada por el CN/CNT. Se aprobaron varios dictámenes ratificando el compromiso del anarcosindicalismo con la resistencia y la colaboración gubernamental y caracterizando a la unidad antifascista expresada en el Frente Popular como la garantía de la victoria, la libertad y la independencia del pueblo español ${ }^{5}$.

Para poder realizar todas estas operaciones políticas, que transgredían la esencia de los principios ideológicos del anarquismo, los comités dirigentes pretendieron asegurar el consenso de la militancia exigiendo el cumplimiento de los acuerdos orgánicos y controlando la prensa. En el otoño de 1936, para disciplinar y cohesionar el movimiento anarcosindicalista y para explicar la línea oficial de colaboración, que llevó a la CNT a ingresar en la Generalitat de Cataluña y en el Gobierno de la República, el CN/CNT y el Comité Peninsular de la FAI (CP/FAI) activaron los mecanismos necesarios para controlar los principales portavoces libertarios: Solidaridad Obrera y Tierra y Libertad. En el verano de 1937 la necesidad de obtener el apoyo de los órganos de expresión se había agudizado al arreciar la crítica anticolaboracionista tras la crisis de mayo. Precisamente por esas fechas comenzaron a circular publicaciones internas, como el Boletín de Orientación Interna de la CNT y el Boletín de Información y Orientación Orgánica del Comité Peninsular de la Federación Anarquista Ibérica, destinadas a homogeneizar la propaganda libertaria, tanto oral como escrita ${ }^{6}$.

En Madrid, la pretensión de establecer el control sobre la prensa se materializó con la fundación de la Comisión de Propaganda Confederal y Anarquista (CPCA), un organismo delegado de las organizaciones libertarias madrileñas cuyo objetivo fundamental consistía en la coordinación y la centralización de toda la propaganda de la Región Centro, con jurisdicción por tanto sobre las provincias de Madrid, Toledo, Guadalajara, Cuenca y Ciudad Libre (Ciudad Real) 7 . Contaba con delegaciones de los Comités Regionales y de las Federaciones Locales de las tres ramas del movimiento; las Federaciones Locales de Ateneos y de Mujeres Libres también estaban representadas ${ }^{8}$.

Los primeros meses de vida de la CPCA fueron un tanto precarios. Se emplearon en definir el ordenamiento interno de la nueva entidad y en establecer los mecanismos de financiación. El 2 de noviembre de 1937 la CPCA 
acordó la racionalización de su estructura con la instauración de un secretariado permanente compuesto de dos Secciones, Actos Públicos y Prensa, una Secretaría General y una Tesorería. Juan Andrés Olmos y Luis Polo, delegados del Comité Regional de la CNT (CR/CNT), fueron nombrados secretario general y tesorero, respectivamente, mientras que a José Alted, de la Federación Local de Sindicatos Únicos, se le encomendó la secretaría de Actos Públicos. La Sección de Prensa la ocupó Luis Zugadi, representante de la Federación Local de Grupos Anarquistas (FL/GGAA). La reestructuración de la CPCA reflejó unas condiciones financieras correlativas. Rechazada la fórmula de las aportaciones igualitarias, se decidió encomendar a los organismos representados la estipulación de unas mensualidades fijas en concordancia con las posibilidades de cada uno. Como era de esperar, las organizaciones sindicales asumieron el grueso de la financiación ${ }^{10}$.

A medida que la CPCA afianzaba su base institucional y económica, acometió su objetivo primordial, el control sobre las publicaciones de la región. Dicho control se pretendía alcanzar siguiendo cuatro vías: realizando un registro completo de la prensa libertaria, monopolizando la distribución de la misma, supervisando la edición de folletos y publicando un boletín pro$\mathrm{pio}^{11}$. El control sobre lo que leía la militancia libertaria madrileña, tanto en la retaguardia como en los frentes, otorgaba un poder de movilización determinante. Las resistencias a la implantación del poder de la CPCA y, por ende, del CN/CNT fueron importantes. La principal oposición provino del Comité Regional de Defensa (CRD), organismo que controlaba la distribución de la prensa entre los militantes encuadrados en el Ejército a través de su propia Comisión de Propaganda, encargada además de editar un periódico propio. El CRD estaba compuesto por tres miembros: Eduardo Val, secretario general, Manuel Salgado, secretario de propaganda, y José García Pradas, director de Frente Libertario. En teoría dicho organismo sólo era una sección del CR/CNT; en la práctica era un poder alternativo.

En marzo de 1938 la FAI organizó un mitin en Madrid y la CPCA acordó publicar un folleto recogiendo los discursos. A pesar de ello, el CRD editó la intervención de Pradas por su cuenta. La polémica estaba servida. El secretario general Olmos explicó a la CPCA lo que García Pradas le había dicho: sólo se trataba de una edición para el frente. Dos meses después, la excusa fue reutilizada para anunciar un libro en Frente Libertario sin el sello de la CPCA. Salgado y García Pradas ofrecieron la posibilidad de una segunda edición; la CPCA exigió el estampado del sello; la posibilidad del consenso se desvanecía ante la rotundidad de la negativa. El 4 de julio Olmos y Alted acudieron a una reunión del CR/CNT en la que el CRD alegó la autonomía a nivel nacional de la Sección Defensa. Por su parte, la CPCA acordó celebrar una reunión extraordinaria con los secretarios de los organismos representados y con Eduardo $\mathrm{Val}^{12}$. 
Dicha reunión tuvo lugar el 14 de julio de 1938. El secretario general de la CPCA recordó las atribuciones originales de la institución, con las que "han cumplido todos a excepción de la Sección Defensa". Julián Fernández y José Gutiérrez, secretarios de las Federaciones Locales de Sindicatos Únicos y de Ateneos, respectivamente, reivindicaron el papel de la Comisión incidiendo en la cuestión de fondo: el nulo control del CR/CNT sobre su Sección de Defensa. Por su lado, José E. Leiva, secretario del Comité Regional de Juventudes Libertarias, y Celedonio Pérez, de la Federación Anarquista de Madrid (FAM; sucesora de la FL/GGAA), mantuvieron una posición de compromiso: aunque reconocían las prerrogativas centralizadoras de la CPCA, defendieron la autonomía de la sección de propaganda del CRD. Finalmente, a propuesta del CR/CNT, se acordó que las ediciones de la Comisión de Propaganda de la Sección Defensa fueran controladas por la CPCA. El mecanismo de subordinación previsto consistía en el establecimiento de un canal de comunicación basado en el diálogo entre Salgado y Tomás Sánchez, a la sazón, secretario de Prensa de la CPCA. A la Comisión de Propaganda del CRD se le concedería la libertad de realizar ediciones destinadas al frente ${ }^{13}$.

A pesar de las componendas, dos semanas después todavía no se habían iniciado las reuniones para activar la relación entre las dos comisiones. Todo lo contrario. Las distancias aumentaron en agosto. García Pradas envió un informe a los Comités Regionales de la CNT, la FAI y la FIJL (Federación Ibérica de Juventudes Libertarias) solicitando que se detuviera la publicación del Boletín de la Comisión de Propaganda Confederal y Anarquista. Denunció poca "finura" en el lenguaje y derroche de papel, además de una incomprensible falta de claridad a la hora de tratar los problemas del Movimiento, falta de "sentido anarquista y confederal": criticó la elección del término "España republicana", en vez de antifascista o trabajadora. El secretario de Prensa Sánchez y el periodista confederal encargado del Boletín, Enrique Jiménez Calderón, presentaron su dimisión. El 10 de septiembre la CPCA celebró una reunión con Pradas para solucionar el asunto contraponiendo al informe original un contrainforme elaborado por Sánchez. Las posiciones se suavizaron y Pradas manifestó no desear ninguna dimisión. Sin embargo, las delegaciones del Comité Regional de Juventudes Libertarias y de la FAM abundaron en los mismos términos del informe del director de Frente Libertario: necesidad de militantes revolucionarios para dar al Boletín la orientación verdaderamente libertaria de la que carecía, librando a la CPCA de la mentalidad burguesa ${ }^{14}$.

Esta coincidencia de criterios entre la FAM y el CRD no era una casualidad. Por el contrario, respondía a una mentalidad compartida basada en una relación de afinidad. Similares argumentos utilizó Celedonio Pérez el 12 de abril de 1938 cuando reivindicó el sentido libertario de la lucha española 
en una carta enviada a la CPCA sobre la orientación del Boletín. Pérez, secretario de la FAM, ejercía mucha influencia sobre García Pradas, "al que había enseñado el anarquismo". En realidad, antes de la sublevación militar de julio de 1936, García Pradas había ingresado en la FAI adhiriéndose a "Los Libertos", el grupo específico que lideraban el propio Pérez y Melchor Rodríguez. En septiembre la delegación de la FAM llevó a la CPCA la propuesta de Salgado, secretario de propaganda del CRD, para nuevo titular de la Sección Prensa. Además, la representación de la FAI madrileña fue de las más beligerantes en las discusiones en torno al informe de García Pradas: propició la reunión del día 10 reclamando la presencia personal del referido y recalcó la necesidad de militantes de solvencia anarquista para dirigir la CPCA, respaldando el fondo ideológico del informe. Por si fuera poco, el secretario Olmos, que había conseguido resolver el problema de las publicaciones con el CRD, pero que se encontraba desgastado y dividido por su cargo en el Ejército, denunció veladamente en la reunión de la Comisión Permanente del 19 de julio la celebración de una entrevista entre Siro Bascones, delegado de la FAM, y David Antona, secretario del CR/CNT, en la que supuestamente Bascones solicitó la secretaría general de la CPCA ${ }^{15}$.

Estos enfrentamientos por el control de la propaganda en la Región Centro reflejaban las divergencias existentes respecto a la línea política marcada por la dirección anarcosindicalista. A partir de la primavera de 1938 el pesimismo y el derrotismo se fueron adueñando de las filas libertarias. Las causas del desastroso encadenamiento de derrotas comenzaron a buscarse en la supuesta pasividad de los comités dirigentes ante el proselitismo comunista y la contrarrevolución negrinista. A raíz de la polémica sobre los Trece Puntos, se iniciaron las divergencias en torno al colaboracionismo entre el $\mathrm{CP} / \mathrm{FAI}$ y el CN/CNT. A duras penas se consiguió que la delegación faísta en el Frente Popular firmara el manifiesto de adhesión a la declaración del Gobierno Negrín. Los grupos de afinidad que dominaban el CP/FAI pretendieron recuperar la pureza revolucionaria renegando del "ministerialismo" y el "gubernamentalismo" que parecían haber contaminado a los comités responsables. Así se expresaba a primeros de mayo Jacinto Toryho, del Grupo " $\mathrm{A}$ ", en el informe que redactó para los Sindicatos explicando las razones de su destitución como director de Solidaridad Obrera. El gobierno contrarrevolucionario estaba asfixiando con su censura al diario barcelonés y los comités dirigentes no hacían nada, inactivos ante la ofensiva contrarrevolucionaria comunista-negrinista. En realidad, Toryho fue destituido por su desacuerdo con la línea política marcada por los comités dirigentes ${ }^{16}$.

Esta desafección hacia la política de resistencia del Gobierno Negrín mostrada por los grupos barceloneses que dominaban el CP/FAI tuvo su contrapartida madrileña en la oposición que articuló el Grupo "Los Libertos", a través del CRD y de la FAM, al establecimiento del poder de la CPCA. 
Sin embargo, la situación en Madrid era diferente. Una acción paralela a la destitución de Toryho era impracticable. La base de poder del CRD era demasiado amplia: tenía bajo su supervisión a la militancia libertaria encuadrada en el Ejército; seguía monopolizando la propaganda en el frente, a pesar de la CPCA; y controlaba los diarios CNT y Frente Libertario. Este poder tenía su origen en el liderazgo ejercido durante el proceso de organización de las columnas de milicianos confederales. En cambio, el poder de Toryho y de su Grupo "A" descansaba principalmente sobre el respaldo de Mariano R. Vázquez. Además, con la partición del territorio republicano en abril de 1938, las comunicaciones con la zona centro-sur se tornaron cada vez más difíciles y la independencia del CRD no dejó de aumentar ante la impotencia del secretario del CR/CNT. Por otro lado, el apoyo del CN/CNT a la CPCA fue, cuanto menos, irregular e insuficiente, considerando la ambición del proyecto. La delegación del CN/CNT sólo acudió a las primeras reuniones; los boletines de orientación llegaban "muy de tarde en tarde"17.

Con la caída de Cataluña en febrero de 1939, la brecha abierta en el seno del anarcosindicalismo desde la primavera de 1938 se hizo insalvable. $\mathrm{Al}$ igual que el Gobierno, el CN/CNT acabó en Francia empujado por las tropas franquistas. El día 10 Mariano R. Vázquez redactó una carta junto a Pedro Herrera, secretario del CP/FAI, para Segundo Blanco, el representante libertario en el Gobierno, en la que los comités dirigentes le daban unas instrucciones a seguir: había que procurarse la participación en los organismos responsables de la evacuación para "salvar a nuestra "militancia»" porque "el gobierno, aunque no lo diga, liquida". Además, los Subcomités fueron reconocidos como la máxima autoridad orgánica de la zona centro-sur mientras no se enviara una delegación. En el Pleno de Regionales del Movimiento Libertario celebrado los días 10 y 11 de febrero una representación enviada ad hoc informó de la intención del CN/CNT de regresar a España para prolongar la resistencia con el objetivo de salvar a la militancia libertaria. El 14 de febrero se difundió una circular del Secretariado Nacional de Defensa que afirmaba que todavía podía "resistirse al enemigo durante unos meses [...]. Resistir para evitar un desastre que nos llevaría al verdadero caos"18.

Sin embargo, el CN/CNT no regresó y el compromiso libertario con la resistencia se fue resquebrajando irremisiblemente. El Subcomité Peninsular de la FAI se manifestaba ya en enero por "la necesidad de que al plantearse la crisis política debería considerarse como anexa la del propio Comité nacional, fiel intérprete del actual gobierno". A mediados de febrero el Subcomité Nacional de la CNT tuvo que frenar los impulsos del teniente coronel anarquista Cipriano Mera, jefe del IV Cuerpo de Ejército. En connivencia con sus mandos de división y con su superior, el jefe del Ejército del Centro, coronel Segismundo Casado, Mera estaba preparando el secuestro de Negrín para obligarle a negociar la paz. Tras consultarlo con Casado, Mera se dirigió 
a Eduardo Val, secretario del CRD, que "consideró que era preciso el acuerdo de la Organización”. Fue entonces cuando el Subcomité Nacional detuvo la iniciativa ${ }^{19}$.

Val aprendió la lección. El CRD preparó un "pleno restringido de militantes" para la adopción de acuerdos sobre la guerra y la política de resistencia. Feliciano Benito, comisario del IV Cuerpo de Ejército y miembro del Grupo "Los Libertos", procuró recalcar que la asistencia se requería por "orden de Val". El protagonismo de la reunión lo retuvieron Salgado y García Pradas, los otros dos miembros del CRD. El primero denunció la propensión dictatorial de Negrín; el segundo recalcó la catástrofe que supondría la toma del poder por los comunistas. De nuevo, la contrarrevolución comunista-negrinista. Manuel Amil fue, como miembro de la comisión enviada a Francia a primeros de mes para contactar con el CN/CNT, el encargado de aportar el patetismo a tan grave momento refiriendo una conversación entre dos militares comunistas sobre las intenciones golpistas de Negrín. "Aunque Manuel Amil tenía fama de receloso y aficionado a las intrigas, nadie puso en tela de juicio sus «escuchas»". El pleno acordó rechazar toda clase de dictadura y concedió a los comités del movimiento libertad para pactar con el resto de las organizaciones antifascistas. Después del pleno, Val reunió a los militantes con mando en el Ejército y les advirtió de la inminencia de la constitución de una Junta para derrocar a Negrín ${ }^{20}$.

Si el Grupo "Los Libertos" contó con una participación central en este Pleno, con la intervención de García Pradas, no menos importante fue su papel en el establecimiento de las relaciones del CRD con la incipiente trama golpista del coronel Casado. El 26 de febrero se celebró una reunión entre el jefe del Ejército del Centro, el socialista Julián Besteiro, un tal Girauta y el líder de "Los Libertos", Melchor Rodríguez, en la que éste último llegó a aceptar la presidencia de la Junta de Defensa que se pretendía crear para efectuar la entrega de Madrid ${ }^{21}$.

Sobre estos acuerdos se sustentó la participación libertaria en el golpe de Casado del 5 de marzo de 1939. Los nombramientos militares del día 3 fueron interpretados como la prueba de que Negrín y el Partido Comunista Español (PCE) pretendían dar un golpe de Estado; la señal que esperaba el CRD para activar su acuerdo. Al día siguiente, Eduardo Val y Manuel Salgado celebraron la reunión con Casado, Mera y Antonio Verardini, jefe de Estado Mayor del IV Cuerpo de Ejército, en la que se decidió responder creando un Consejo Nacional de Defensa. El manifiesto difundido por Unión Radio la medianoche del día 5 lo redactó García Pradas: "No puede tolerarse que en tanto se exige del pueblo una resistencia organizada, [...] unos cuantos privilegiados preparen su vida en el extranjero" 22 . El compromiso libertario con la resistencia había devenido en traición a la República. 


\section{BIBLIOGRAFÍA}

CASANOVA, Julián: De la calle al frente. El anarcosindicalismo en España (1931-1939), Crítica: Barcelona, 1997 [Reeditado en 2006].

CASANOVA, Julián: República y Guerra Civil. Vol. 8. Historia de España, dirigida por Josep Fontana y Ramón Villares, Crítica-Marcial Pons: Barcelona-Madrid, 2007.

CATTINI, Giovanni C. y SANTACANA, Carles: "El anarquismo durante la Guerra Civil. Algunas reflexiones historiográficas”, Ayer, no 45 (2002), pp. 197-219.

DOMINGO, Alfonso: "Melchor Rodríguez y Los Libertos", Germinal. Revista de estudios libertarios, $\mathrm{n}^{\circ} 6$ (2008), pp. 81-107.

GALLEGO, Gregorio: "La CNT acuerda sublevarse contra el doctor Negrín”, Historia y Vida. Extra n 4: Testimonios de la guerra de España (1974). Disponible en: www.sbhac.net/Republica/TextosIm/CNTSubleva/CNTSubleva.htm (13 de enero de 2010). 2004.

GUZMÁN, Eduardo de: Madrid rojo y negro, Editorial Oberon: Madrid,

IÑIGUEZ, Miguel: Esbozo de una enciclopedia histórica del anarquismo español, Fundación de Estudios Libertarios Anselmo Lorenzo: Madrid, 2001

MERA, Cipriano: Guerra, exilio y cárcel de un anarcosindicalista, Ruedo Ibérico: París, 1976 [Reeditado por La Malatesta Editorial: Madrid, 2006].

NAVARRO Y COMAS, Rocío: "La palanca de la Revolución. El control de la prensa por el Comité Peninsular de la FAI (19361939)", en MORALES MOYA, Antonio: Las claves de la España del siglo XX. Ideologías y movimientos politicos, vol. IV, Sociedad Estatal "España Nuevo Milenio" (SEENM): Madrid, 2001, pp. 315 334.

PEIRATS, José: La CNT en la revolución española, tomo 3, Ruedo Ibérico: París, 1971 [1 ${ }^{\mathrm{a}}$ ed. de 1951-1953].

TAVERA, Susanna: Solidaridad Obrera. El fer-se i desfer-se d'un diari anarcosindicalista (1915-1939), Diputación de Barcelona: Barcelona, 1992.

TAVERA, Susanna: "La historia del anarquismo español: una encrucijada interpretativa nueva", Ayer, no 45 (2002), pp. 13-37.

TAVERA, Susanna y UCELAY-DA CAL, Enric: "Grupos de afinidad, disciplina bélica y periodismo libertario, 1936-1938”, Historia Contemporánea, no 9 (1993), pp. 167-190.

VIÑAS, Ángel: El honor de la República. Entre el acoso fascista, la hostilidad 
británica y la política de Stalin, Crítica: Barcelona, 2008.

VIÑAS, Ángel y HERNÁNDEZ SÁNCHEZ, Fernando: El desplome de la República, Crítica: Barcelona, 2009.

\section{NOTAS}

${ }^{1}$ TAVERA, Susanna y UCELAY-DA CAL, Enric: "Grupos de afinidad, disciplina bélica y periodismo libertario, 1936-1938”, Historia Contemporánea, no 9 (1993), pp. 167-168 y 190; TAVERA, Susanna: "La historia del anarquismo español: una encrucijada interpretativa nueva", Ayer, no 45 (2002), pp. 29-31 y CATTINI, Giovanni C. y SANTACANA, Carles: "El anarquismo durante la Guerra Civil. Algunas reflexiones historiográficas", Ayer, $\mathrm{n}^{\circ} 45$ (2002), pp. 210-214 y 218-219.

${ }^{2}$ Todo lo anterior a partir de CASANOVA, Julián: República y Guerra Civil. Vol. 8. Historia de España, dirigida por Josep Fontana y Ramón Villares, Crítica-Marcial Pons: Barcelona-Madrid, 2007; VIÑAS, Ángel: El honor de la República. Entre el acoso fascista, la hostilidad británica y la politica de Stalin, Crítica: Barcelona, 2008 y VIÑAS, Ángel y HERNÁNDEZ SÁNCHEZ, Fernando: El desplome de la República, Crítica: Barcelona, 2009.

${ }^{3}$ Tanto el Dictamen sobre el tercer punto del orden del día del Pleno Nacional de Regionales: "Linea politica-social a seguir" como el Manifiesto del Pleno Nacional del Movimiento Libertario CNT-FAIFIJL de 17 de septiembre en Valencia se adjuntaron a la Circular $n^{\circ} 32$ del CN/CNT de 18 de septiembre de 1937, Centro Documental de la Memoria Histórica de Salamanca (CDMH; antigua Sección Guerra Civil del Archivo Histórico Nacional). Serie Político-Social (PS). Carpeta 527 de Madrid, expediente 31. Las derivas radicales se reflejaron en la recuperación de un cierto sindicalismo antipolítico en el Pleno de Regionales de finales de mayo: se acordó "no prestar colaboración directa ni indirecta al nuevo Gobierno" y "procurar el entendimiento con la U.G.T., para llevar comunmente [sic] la tarea de oposición al Gobierno" ("Acuerdos del Pleno Nacional de Regionales celebrado los días 23 y sucesivos de mayo de 1937" transmitidos a las Regionales en la Circular n ${ }^{\circ} 6$ del CN/CNT de 27 de mayo, CDMH. PS. Carpeta 39 de Bilbao, exp. 24). El comienzo de las "gestiones oficiosas cerca de Negrín" en el Acta del Pleno Nacional de Regionales celebrado los días 2 y sucesivos de junio de 1937, CDMH. PS. Carpeta 39 de Bilbao, exp. 24. El programa, Ante el momento español. Programa mínimo elaborado por la CNT para realizar una auténtica politica de guerra, firmado por Mariano R. Vázquez el 3 de junio de 1937, se conserva en CDMH. PS. Carpeta 663 de Madrid, exp. 46. El proyecto del Frente Popular Antifascista y su fracaso pueden seguirse en una Circular del CN/CNT de 22 de junio de 1937, CDMH. PS. Carpeta 39 de Bilbao, exp. 24.

${ }^{4}$ El cenetista Segundo Blanco asumió la cartera de Instrucción Pública y Sanidad; el ugetista Ramón González Peña la de Justicia. La ruta seguida por la CNT para su vuelta al Gobierno la explica el CN/CNT en su Circular $n^{\circ} 7$ a los Comités Locales y Comarcales de 9 de abril de 1938, CDMH. PS. Carpeta 663 de Madrid, exp. 30. El programa de unidad de acción CNT-UGT se recoge en PEIRATS, José: La CNT en la revolución española, tomo 3, Ruedo 
Ibérico: París, 1971, pp. 36-41.

${ }^{5}$ Los dictámenes y las declaraciones públicas aprobados por el Pleno fueron comunicados a la militancia anarcosindicalista mediante la Circular $n^{\circ} 35$ del CN/CNT de 11 de noviembre de 1938, CDMH. PS. Carpeta 663 de Madrid, exp. 30. La cita de la alocución radiada de Mariano R. Vázquez del 24 de junio en el folleto El Frente Popular muestra su adhesión al discurso que el Presidente del Consejo de Ministros Dr. Negrín pronunció en Madrid el 18 de junio de 1938, Ediciones Españolas: 1938, p. 25.

${ }^{6}$ Del Boletin de Información y Orientación de la FAI se conservan ocho números en la hemeroteca del CDMH; el primero se publicó el $1^{\circ}$ de mayo de 1937, el último el 12 de septiembre. Para Solidaridad Obrera ver TAVERA, Susanna: Solidaridad Obrera. El fer-se i desfer-se d'un diari anarcosindicalista (1915-1939), Diputación de Barcelona: Barcelona, 1992 y TAVERA y UCELAYDA CAL: op. cit., de donde procede lo del Boletín de Orientación Interna de la CNT, p. 185. Para Tierra y Libertad ver NAVARRO Y COMAS, Rocío: "La palanca de la Revolución. El control de la prensa por el Comité Peninsular de la FAI (1936-1939)", en MORALES MOYA, Antonio: Las claves de la España del siglo XX. Ideologias y movimientos políticos, vol. IV, Sociedad Estatal "España Nuevo Milenio" (SEENM): Madrid, 2001, pp. 315-334. El repunte del anticolaboracionismo tras los Hechos de Mayo en CASANOVA, Julián: De la calle al frente. El anarcosindicalismo en España (1931-1939), Crítica: Barcelona, 1997, p. 228.

${ }^{7}$ Por carta de 25 de junio de 1937, Eustaquio Rodríguez, el primer secretario de la nueva institución, reconoció al secretario de la Federación Provincial de las Juventudes Libertarias de Toledo que la CPCA se había "constituido para coordinar la propaganda de los organismos confederal, anarquista y juvenil en la Regional Centro por acuerdos tomados en plenos nacionales": CDMH. PS. Carpeta 894 de Madrid, exp. 57. La CPCA celebró su reunión constitutiva el 5 de junio de 1937; se acordó redactar una nota de presentación, se resaltó su vinculación con la Sección de Propaganda del CN/CNT y se anunció el propósito de realizar una centralización orgánica de toda la propaganda de la región: Acta de la reunión celebrada por la Comisión de Propaganda Confederaly Anarquista el día 5 de junio de 1937 (a partir de ahora, Acta CPCA/ Fecha de la reunión). Las actas de casi todas las reuniones, del 5 de junio de 1937 al 23 de enero de 1939, se conservan en CDMH. PS. Carpeta 1220 de Madrid, exp. 2; el de la reunión de 13 de febrero de 1939, en Carpeta 2349 de Madrid. El patrocinio del proyecto por parte del CN/CNT se puso de manifiesto con la asistencia de un delegado, al menos a las primeras reuniones.

${ }^{8}$ En la reunión de 23 de enero de 1939 se aprobó por unanimidad la incorporación de una delegación permanente de la Federación Regional de Mujeres Libres (Acta CPCA/ 23 de enero de 1939).

${ }^{9}$ La credencial a favor de Luis Zugadi, firmada a 31 de mayo de 1937 por Manuel Ramos, secretario de la FL/GGAA, se conserva en CDMH. PS. Carpeta 1335 de Barcelona, exp. 2. El establecimiento del secretariado de cuatro miembros se realizó de acuerdo con el dictamen aprobado en reunión de 30 de octubre de 1937 y redactado por una ponencia compuesta 
por Eustaquio Rodríguez, secretario de la CPCA, Miguel Caballero y Juan Andrés Olmos (Acta CPCA/ 6 y 30 de octubre y 2 de noviembre de 1937). El texto de la ponencia se conserva adjuntado a Acta CPCA/ 20 de octubre de 1937.

${ }^{10}$ Las representaciones fueron anunciando sus aportaciones económicas durante agosto y septiembre de 1937. En Acta CPCA/ 21 de noviembre de 1938 el tesorero reveló las fuentes de financiación de la CPCA: el Comité Regional y la Federación Local confederales comprometían 3.000 pesetas al mes; las representaciones faístas y la Federación de Ateneos 1.000; las delegaciones juveniles recordaron la imposibilidad de afrontar una cantidad fija por parte de sus organizaciones.

${ }^{11}$ En la primera reunión se acordó confeccionar un archivo de prensa e implantar el control de la CPCA sobre las publicaciones libertarias (Acta CPCA/ 5 de junio de 1937). El proyecto del "archivo completo" de prensa para "mantener un control perseverante y meticuloso de todas las manifestaciones de la propaganda oral y escrita" se elevó a consigna general con la Circular de la Sección de Información, Propaganda y Prensa del CN/CNT de 14 de agosto de 1937, CDMH. PS. Carpeta 593 de Madrid, exp. 14.

${ }^{12}$ Acta CPCA/ 11 de julio de 1938. Un resumen del mitin faísta celebrado en el Monumental Cinema de Madrid el día 6 de marzo en el Boletín de la Comisión de Propaganda Confederal y Anarquista, 15 de marzo de 1938. La polémica por la edición del folleto en Acta CPCA/ 7, 15 y 28 de marzo. Las negociaciones para llegar a un acuerdo entre la CPCA y el CRD sobre la publicación del libro a partir de Acta CPCA/ 23 y 30 de mayo, 14, 21 y 27 de junio y 4 y 11 de julio. La intención de la CPCA sólo consistía en poner su sello y en controlar la distribución, no la edición ni la organización de la propaganda en los frentes, que fueron reconocidas como prerrogativa de la Sección Defensa en agosto (Acta CPCA/ 6 de agosto de 1937).

13 Acta CPCA/ 14 de julio de 1938. Tomás Sánchez sucedió a Zugadi en la secretaría de Prensa tras la muerte de éste en febrero de 1938, aunque no tomó posesión hasta mayo debido al retraso del primer sustituto (Acta CPCA/ 16 de mayo de 1938).

${ }^{14}$ Acta de la reunión extraordinaria celebrada en el domicilio de la Comisión de Propaganda Confederal y Anarquista entre sus Organismos componentes y el compañero García Pradas el día 10 de septiembre de 1938, CDMH. PS. Carpeta 1220 de Madrid, exp. 2. El informe de Pradas y el contrainforme de Sánchez fundidos en un solo documento mecanografiado se conserva adjunto a Acta CPCA/ 22 de agosto de 1938 bajo el título de Respuesta al informe presentado por el compañero García Pradas, director de "CNT" a los Comités Regionales del Centro FAI-Confederaly FIJL. Las dimisiones de Sánchez y Calderón en Acta CPCA/ 5 de septiembre. La ineficacia de los acuerdos de la reunión del 14 de julio en Acta CPCA/ 26 de julio. El Boletín de la Comisión de Propaganda Confederal y Anarquista comenzó a publicarse en enero de 1938 por acuerdo de la CPCA del mes anterior (Acta CPCA/ 27 de diciembre de 1937).

${ }_{15}$ Acta de la reunión celebrada entre los miembros de la Comisión de Propaganda Confederaly Anarquista, CDMH. PS. Carpeta 1220 de Madrid, exp. 2; Olmos fue nombrado Capitán Mayor de For- 
tificaciones el 3 de mayo de 1938 según Acta CPCA/ 3 de mayo. La misiva del secretario de la FAM, mucho más sutil que el informe, se encuentra en CDMH. PS. Carpeta 894 de Madrid, exp. 53. Para Celedonio Pérez, en la guerra española se enfrentaban "dos conceptos que se resumen en el del absolutismo más bárbaro y el que estima y respeta la libertad y la personalidad humana". En Acta CPCA/ 11 de abril de 1938 se refiere la protesta de la delegación local de la FAI por la misma cuestión. La influencia de Pérez sobre Pradas en DOMINGO, Alfonso: "Melchor Rodríguez y Los Libertos", Germinal. Revista de estudios libertarios, $\mathrm{n}^{\circ} 6$ (2008), p. 85. El ingreso prebélico de García Pradas en "Los Libertos" en IÑIGUEZ, Miguel: Esbozo de una enciclopedia histórica del anarquismo español, Fundación de Estudios Libertarios Anselmo Lorenzo: Madrid, 2001, p. 257. La propuesta de Salgado como nuevo secretario de Prensa en Acta CPCA/ 26 de septiembre de 1938; otras delegaciones, como las del CR/CNT y de la Federación Local de Ateneos, eligieron también a Salgado y a Pradas en un intento de apartarles del CRD y obligarles a centrarse en cuestiones meramente profesionales (Acta CPCA/ 3 de octubre de 1938). Las intervenciones de la representación faísta en Acta CPCA/ 5 de septiembre de 1938 y Acta de la reunión extraordinaria... (ver nota anterior).

${ }^{16} \mathrm{El}$ informe de Toryho, de donde proceden los entrecomillados, se titula Destitución fulminante del compañero Jacinto Toryho de su cargo de Director de "Solidaridad Obrera". Las razones de su cese en Informe sobre "Solidaridad Obrera" del Comité Ejecutivo del Movimiento Libertario de Cataluña; ambos documentos en CDMH. PS. Carpeta 1307 de Barcelona, exp. 14. El pesimismo y el derrotismo unido a la denuncia de las supuestas maniobras contrarrevolucionarias en PEIRATS: op. cit., pp. 98-99. La controversia sobre los Trece Puntos entre el CN/CNT y el CP/FAI en PEIRATS: op. cit., pp. 87-99. El CP/FAI estaba dominado por los Grupos "Nervio" (Pedro Herrera y Germinal de Sousa) y "A" (Jacobo Prince).

${ }^{17}$ Acta CPCA/ 5 de diciembre de 1938. Para las raíces del poder del CRD, ver GUZMÁN, Eduardo de: Madrid rojo y negro, Editorial Oberon: Madrid, 2004. La relación de Rodríguez Vázquez con Toryho y su grupo de afinidad en TAVERA y UCELAY-DA CAL: op. cit., pp. 175 y 180-182. El secretario Antona confesó a Olmos en una entrevista el escaso control que ejercía sobre la Sección Defensa (Acta CPCA/ 30 de mayo de 1938). En las Actas de la CPCA se recoge sólo una orientación enviada directamente por el CN/CNT (Acta CPCA) 15 de marzo de 1938).

${ }^{18}$ PEIRATS: op. cit., pp. 285-286. Las instrucciones de Vázquez y Herrera pueden leerse en PEIRATS: op. cit., pp. 286-288. La intención del CN/CNT en PEIRATS: op. cit., p. 283. La necesidad de prolongar la resistencia para garantizar la salvación de la militancia en la Circular-Informe sobre la caída de Cataluña del CN/CNT de 8 de febrero de 1939, recogida en PEIRATS: op. cit., pp. 325-326.

${ }^{19}$ La reacción del Subcomité Nacional de la CNT y el plan de secuestro en MERA, Cipriano: Guerra, exilio y cárcel de un anarcosindicalista, Ruedo Ibérico: París, 1976, pp. 196-197, de donde procede el entrecomillado (p. 197). Las palabras del Subcomité Peninsular se pronunciaron en el Pleno de Regionales de la FAI celebrado el día 19; citado en PEIRATS: op. cit., p. 273. 
${ }^{20}$ La narración del Pleno y los entrecomillados están sacados de GALLEGO, Gregorio: "La CNT acuerda sublevarse contra el doctor Negrín", Historia y Vida. Extra n 4: Testimonios de la guerra de España (1974). Disponible en: www.sbhac.net/Republica/TextosIm/CNTSubleva/CNTSubleva.htm (13 de enero de 2010).

${ }^{21}$ Información procedente de un confidente de Palmiro Togliatti referida en Notas Manuscritas de Togliatti, Archivo Histórico del PCE (AHPCE), Internacional Comunista, 137/4, citado en VIÑAS y HERNÁNDEZ SÁNCHEZ: op. cit., p. 286. Melchor Rodríguez no llegó a presidir nada pero sí que se encargó, por orden de los golpistas y como alcalde de facto, de entregar Madrid a las tropas franquistas el día 28 de marzo: DOMINGO: op. cit., pp. 103104.

${ }^{22}$ Citado en MERA: op. cit., p. 205. La interpretación de los nombramientos y la reunión del día 4 en MERA: op. cit., pp. 200-202. 